\title{
Maternal Correlates of Growth in Toddler Vocabulary Production in Low-Income Families
}

\section{Citation}

Pan, Barbara A., Meredith L. Rowe, Judith D. Singer, and Catherine E. Snow. 2005. Maternal Correlates of Growth in Toddler Vocabulary Production in Low-Income Families. Child Development 76, no. 4: 763-782.

\section{Published Version}

doi:10.1111/1467-8624.00498-i1

\section{Permanent link}

http://nrs.harvard.edu/urn-3:HUL.InstRepos:13041209

\section{Terms of Use}

This article was downloaded from Harvard University's DASH repository, and is made available under the terms and conditions applicable to Other Posted Material, as set forth at http:// nrs.harvard.edu/urn-3:HUL.InstRepos:dash.current.terms-of-use\#LAA

\section{Share Your Story}

The Harvard community has made this article openly available.

Please share how this access benefits you. Submit a story.

Accessibility 


\title{
Maternal Correlates of Growth in Toddler Vocabulary Production in Low-Income Families
}

\author{
Barbara Alexander Pan \\ Harvard Graduate School of Education
}

\author{
Meredith L. Rowe \\ University of Chicago
}

\author{
Judith D. Singer and Catherine E. Snow \\ Harvard Graduate School of Education
}

\begin{abstract}
This study investigated predictors of growth in toddlers' vocabulary production between the ages of 1 and 3 years by analyzing mother-child communication in 108 low-income families. Individual growth modeling was used to describe patterns of growth in children's observed vocabulary production and predictors of initial status and between-person change. Results indicate large variation in growth across children. Observed variation was positively related to diversity of maternal lexical input and maternal language and literacy skills, and negatively related to maternal depression. Maternal talkativeness was not related to growth in children's vocabulary production in this sample. Implications of the examination of longitudinal data from this relatively large sample of low-income families are discussed.
\end{abstract}

Parental reports on children's productive vocabularies during infancy and toddlerhood document large individual variation in vocabulary size across early development (Fenson et al., 1994). Based on a cross-sectional parental report study of more than 1,800 middle-class infants and toddlers, Fenson et al. (1994) found that 12-month-olds at the median produced fewer than 10 different words, whereas children of the same age at the 90th percentile produced 20 to 40 words. By 30 months, children at the median reportedly produced more than 500 words, children at the 10th percentile produced 250 to 350 words, and children at the 90th percentile produced about

The findings reported here are based on research conducted as part of the national Early Head Start Research and Evaluation Project funded by the Administration on Children, Youth and Families (ACYF), U.S. Department of Health and Human Services through Grant 90YF0009 to Harvard University Graduate School of Education. The research was conducted in collaboration with Early Education Services in Brattleboro, Vermont. The first and fourth authors are members of the Early Head Start Research Consortium. The consortium consists of representatives from 17 programs participating in the evaluation, 15 local research teams, the evaluation contractors, and ACYF. The content of this publication does not necessarily reflect the views or policies of the Department of Health and Human Services. The analyses and writing of this paper was supported by an AERA/OERI dissertation grant to the second author. The authors wish to express their gratitude to their program partner and to the participating families.

Correspondence concerning this article should be addressed to Barbara Alexander Pan, Larsen Hall, Harvard Graduate School of Education, Cambridge, MA 02138. Electronic mail may be sent to barbara_pan@harvard.edu.
650 words. Such variation could reflect differences in the age at onset of vocabulary acquisition or differences in the rate of growth. Goldfield and Reznick (1990), also using parental report, found that for most of the 18 middle-class children they studied, growth started with a period of slow word accumulation, followed by a prolonged period of accelerated word learning, beginning somewhere between 14 and 22 months. Goldfield and Reznick's study is notable because it was a longitudinal study that charted children's individual growth trajectories, albeit for only a small number of children.

Most of the limited longitudinal work on early vocabulary has examined growth in measures designed to estimate total vocabulary size. For example, Huttenlocher, Haight, Bryk, Seltzer, and Lyons (1991) used children's cumulative vocabulary production across several observations as an index of vocabulary size. Although groundbreaking in applying individual growth modeling to the study of infant and toddler vocabulary growth, Huttenlocher et al.'s study was also limited to a small sample (22 middle-class toddlers). Furthermore, the cumulation assumption that words young children produce at one time point are thereafter always a part of their productive lexicon has been questioned (Rescorla, 1980). We do not yet know whether children's actual observed word production yields results similar to those documented for cumulative vocabulary size. To our knowledge, there have been no published

(C) 2005 by the Society for Research in Child Development, Inc. All rights reserved. 0009-3920/2005/7604-0001 
reports of growth over time in children's observed vocabulary use.

Longitudinal studies of children's observed language production have historically focused on single cases or on small groups of children (e.g., Brown, 1973; see also MacWhinney, 2000). Hart and Risley's (1995) study, in which 42 children were followed from before their first birthday to about age 3, represents perhaps the largest sample of children for whom longitudinal vocabulary production data across early development are available. Their data provide a glimpse of individual growth trajectories and differences both within and across social classes in children's vocabulary size (i.e., cumulative vocabulary use). Even so, Hart and Risley's sample included only 6 children from low-income families. Longitudinal data on children in those 6 families constitute nearly the entirety of what we know about observed vocabulary production of infants and toddlers from low-income families. Clearly, observation of such a small sample of children increases the likelihood that variability in vocabulary use and growth rates may be underestimated, perhaps seriously so.

Thus, several gaps remain in the literature regarding observed vocabulary production by infants and young toddlers. Data based on longitudinal observation are needed for larger samples of children, particularly those from low-income families, and examination of both growth over time in children's observed vocabulary use and predictors of growth rates is needed to complement what we know about growth in cumulative vocabulary size.

Previous research has documented several child factors that contribute to individual differences in vocabulary size or use. For example, girls appear to develop vocabulary more quickly than do boys in the early stages (Bauer, Goldfield, \& Reznick, 2002; Bornstein, Haynes, \& Painter, 1998; Fenson et al., 1994; Huttenlocher et al., 1991). Likewise, firstborn children have larger vocabularies (Hoff-Ginsberg, 1998) and faster rates of vocabulary growth (Goldfield \& Reznick, 1990) than later born children.

Other factors involve environmental, or input, factors. Parents who direct more speech to their children have children with larger vocabularies (Hart \& Risley, 1995) and faster vocabulary growth over time (Huttenlocher et al., 1991). Comparisons across socioeconomic groups show that less educated, less advantaged parents tend to talk less and use fewer different words with their children (Hart \& Risley, 1995; Hoff-Ginsberg, 1991). Thus, children growing up in economically disadvantaged environments may be at risk for academic difficulties related to vocabulary acquisition in that they are exposed to less verbal input. For example, many children entering Head Start at age 3 are already behind their middle-income peers in vocabulary development (Vernon-Feagans, 1996). The ramifications of early deficits in vocabulary size can have long-lasting negative effects on children's reading achievement during the primary school years (Snow, Burns, \& Griffin, 1998). At the same time, some studies have pointed to considerable variability in the quantity and quality of maternal child-directed speech among low-income families (DeTemple \& Snow, 1996; Pan \& Rowe, 1999). These findings, along with those of Hart and Risley (1995), need to be replicated with larger samples of children from lowincome families using analytic methods that also model individual change in input factors if we are to have a fuller understanding of variation across children from low-income families.

Research with middle-class families suggests that maternal education, as well as maternal vocabulary and literacy skills, relate to child language skills, both directly and indirectly through maternal vocabulary use (Bornstein et al., 1998; National Institute of Child Health and Human Development [NICHD], 2000). These factors, then, are prime candidates in any initial investigation of predictors of vocabulary use by children from low-income families.

Socioemotional aspects of mother-child interactions have been less widely studied as predictors of child language development (Belsky, 1984), despite evidence that mothers experiencing more stress and depression talk less to their children (Breznitz \& Sherman, 1987; Lovejoy, Graczyk, O'Hare, \& Newman, 2000). The role of maternal stress and depression may be particularly important to consider when studying low-income families living in rural communities, where stress and depression are prevalent (Belle, 1990) and where social support may be limited. Related research has shown that maternal mental health factors are highly predictive of children's socioemotional development and of adjustment problems such as disruptive behavior (Radke-Yarrow, Nottelmann, Martinez, Fox, \& Belmont, 1992).

A final gap in the literature that this study aims to address has to do with the potential influence of nonverbal communicative input, such as that provided by maternal pointing. Most work on the influence of communicative input on children's vocabulary growth has examined only verbal input. Recent work has begun to examine the prevalence of nonverbal input, specifically pointing, and the particular purposes such gestures serve in parent-child 
interactions. Results show that maternal pointing is related to amount of maternal talk (Rowe, 2000), frequently accompanies object labeling (Murphy, 1978), reinforces the message conveyed through speech (Iverson, Capirci, Longobardi, \& Caselli, 1999), and helps establish periods of joint attention between dyads (Iverson, Capirci, \& Caselli, 1994). Episodes of joint attention around objects are conducive to labeling and have been shown to facilitate children's acquisition of object names (Tomasello \& Farrar, 1986). Thus, a complete investigation of childdirected communication needs to include nonverbal as well as verbal input as predictors of child vocabulary growth.

To summarize, the goals of the current study were: (a) to provide descriptive information about observed vocabulary production of a relatively large sample of children from low-income families, (b) to use individual growth modeling to describe growth over time in children's vocabulary production, and (c) to investigate whether rate in change over time in vocabulary production of children from low-income families is predicted by the same factors identified earlier for middle-class children. To address these questions, we examined data from 108 low-income families residing in rural New England and participating in the national evaluation of Early Head Start (EHS). Because half of the families were randomly assigned to the program group and received services from the program during the period under study, the possible effect of family program status on child vocabulary growth was also considered. We used growth modeling techniques to describe change over time in children's observed vocabulary production. Control variables included child gender and birth order, maternal age, family income, and program status. Predictors of children's rate of growth in vocabulary use during the 2nd and 3rd years of life were maternal verbal and nonverbal communicative input, maternal education, maternal language and literacy skills, and maternal depression. The specific research questions were:

1. What are the patterns of growth in observed vocabulary production among children from low-income families between 1 and 3 years of age?

2. Are the rates of change in children's observed vocabulary production related to maternal communicative input, maternal education, maternal language and literacy skills, or maternal depression, controlling for child gender and birth order, maternal age, family income, and family participation in an intervention program?

\section{Method}

\section{Participants}

Participants were drawn from a larger study of 146 mother-child dyads participating in a national longitudinal study on the effectiveness of EHS. At entry to the study, families were living in a rural New England community and qualified for public assistance. Families who had any child enrolled in a similar intervention program in the previous 5 years or in any federal, state or local program with similar services in the previous 12 months were not eligible to participate. Recruitment procedures included posting flyers, going door to door, and contacting other service providers in the area. Families were continuously recruited during the 27-month recruitment period, resulting in a sample of increasing size over time. The local EHS program being studied exhausted recruitment capabilities and was confident that the 146 families found were all the eligible families in the county during the allowed period of recruitment. Families enrolled in the study during the mother's pregnancy or before the target child's first birthday. Most parents were White (91\%) and used English as their home language (99\%). Firstborn children made up $49 \%$ of the sample. Families were randomly assigned upon entry to the study to either the program or a comparison group. All data examined in the current study were collected on both program and comparison families.

The 119 families originally targeted for the current study were those who agreed to be videotaped on at least one of three occasions. One of those 119 families was excluded because English was not the primary language in the home, and therefore the target child was not a native English speaker. Three additional families were excluded because custody of the child changed before the child's third birthday. Seven additional families were excluded because of incomplete data collection on necessary measures other than the videotaped interaction. Therefore, the final sample size was 108 families. Data from one family at the third data collection point only were excluded because the filming conditions did not meet project standards.

Of these 108 families, 57 dyads had data for all three waves, 27 had data for only two waves, and 24 had data for only one wave (see Figure 1a). One of the advantages of using individual growth modeling is that the multilevel model for change is designed to deal with longitudinal data sets such as this one in which there are varying numbers of waves per person and variable spacing of these waves. Thus, all 108 dyads could be included in the analysis (Singer \& Willett, 2003). Although dyads with fewer than 

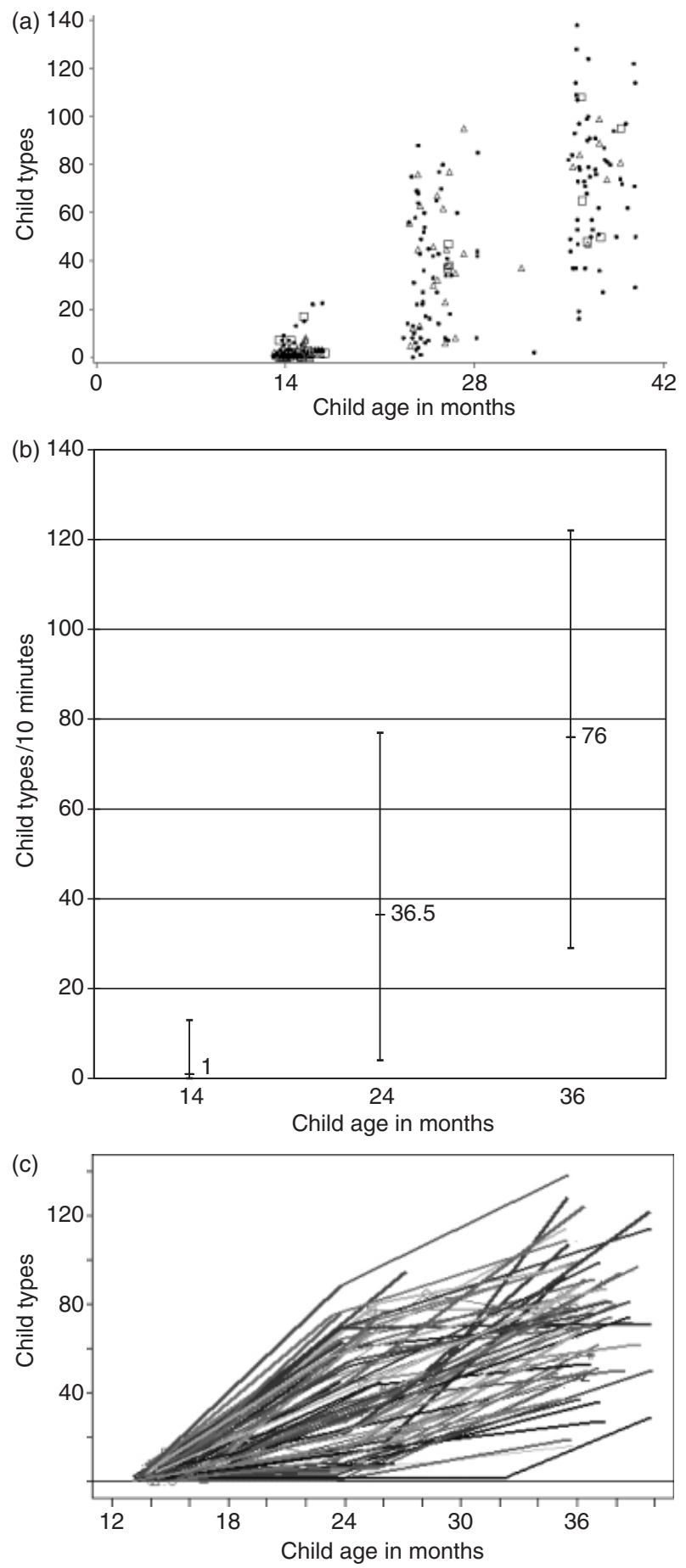

Figure 1. (a) Distribution of children's word types at each wave highlighting those who have one wave (square symbol), two waves (triangle symbol), or three waves (dot) of data. (b) Distribution of children's word types at each wave (median and 5th and 95th percentiles). (c) Empirical growth plots of child vocabulary production by age $(N=108)$.

three waves provided less, or no, information about within-person variation - and hence did not contribute to the estimation of variance components - they did contribute to the estimation of fixed effects (the structural portion of the individual growth model).

Visual inspection of the patterns of missingness based on child vocabulary production (Figure 1a) indicated no systematic differences, with the data for children with just one or two waves of data indistinguishable from the data for children with all three waves. ${ }^{1}$ In addition, we conducted empirical tests of any measurable difference between the trajectories of individuals with different patterns of missingness (Hedeker \& Gibbons, 1997), and no systematic pattern emerged.

\section{Procedure}

Data collection in the larger EHS study included child assessments, maternal interviews, home and family observations, and child care observations for children in out-of-home care at least $10 \mathrm{hr}$ per week. The results presented here are based on background demographic information and questionnaire data collected at baseline (study entry) and spontaneous speech samples based on videotaped mother-child interaction collected at up to three time points. As shown in Figure 1a, child ages varied around the targeted 14-, 24- and 36-month ages. As expected, models fit using the child's actual age fit better than models fit using the child's target (rounded) age; we therefore used the more precise metric in the structural portion of the individual growth models.

At each home visit, dyads were provided with three bags containing a book and various toys. At 14 months, the book provided was a wordless book, Good Dog Carl by Alexandra Day (1996); at 24 and 36 months it was The Very Hungry Caterpillar by Eric Carle (1983). At all three time points the toys were age-appropriate toys intended to facilitate talk and pretend play (e.g., a toy cooking set, an ark with animals). This procedure is similar to that used by Vandell (1979) and others (e.g., Snow, Pan, ImbensBailey, \& Herman, 1996). Mothers were asked to begin with the bag containing the book, then move on to each of the other two bags in turn. Dyads were not required to play with contents of all three bags. Pace and transition from one bag to the next during the 10-min observation period was determined by mother and child. Dyads varied in the number of minutes they chose to spend with the bag containing the book (14 months: $M=1.8, S D=1.2 ; 24$ months: $M=1.6, S D=1.2 ; 36$ months: $M=1.9, S D=1.2)$. At each wave, number of minutes spent with the book was positively correlated with all measures of maternal communication but was unrelated to child vocabulary production. 
The videotaped interactions were transcribed using the CHAT conventions of the Child Language Data Exchange System (CHILDES; MacWhinney, 2000). Transcripts included both verbal and nonverbal (including pointing) behavior by mother and child. The unit of transcription was the verbal utterance or nonverbal communicative action or gesture bounded by grammatical closure or a pause of more than $2 \mathrm{~s}$ or transition in speaker. A second transcriber verified each transcript to ensure that all intelligible talk was transcribed and that transcription conventions were followed. Spelling consistency was again verified at the point at which frequency lists were automatically generated to ensure that number of word types was accurate.

A pointing gesture was defined as any use of the index finger by mother or child to point to a person or object. Shift in object being pointed to constituted a new instance of pointing. Duration of a given point was not measured. Instances in which the mother guided the child's hand and helped the child point, and those in which mother or child used something other than an index finger to point (e.g., a plastic spoon) were not considered pointing gestures. Reliability of the occurrence of pointing gestures was assessed for a randomly selected $10 \%$ of videotaped data at each time point, resulting in interrater agreement of $87 \%$ at 14 months (based on 100 points), $84 \%$ at 24 months (based on 87 points), and $82 \%$ at 36 months (based on 172 points). Overall agreement for all points combined was $84 \%$.

\section{Measures}

Child vocabulary production. Automated analyses of the transcripts yielded number of different words (types) and total number of words (tokens) produced by mother and child at each observation. Child vocabulary production at each age was measured using the number of word types produced during the 10min mother-child interaction. This sampling approach has been used by other researchers studying both children's vocabulary production and maternal input before child age 3 (e.g., Bornstein et al., 1998; Corkum \& Dunham, 1996; Pan, Imbens-Bailey, Winner, \& Snow, 1996; Pan, Rowe, Spier, \& TamisLeMonda, 2004; Rollins, 2003). Number of child word types in this sample has been shown to be congruent with concurrent parental report of children's productive vocabulary (Pan et al., 2004).

Several decisions were made as to what constitutes a word type. Morphologically inflected variants of words (e.g., bike and bikes, talk and talking) were considered a single type, but alternate forms of words (e.g., bike and bicycle) were considered two word types. Words that were produced in imitation of the mother were considered part of the corpus of child-produced words. All words in each transcript were examined to ensure that word counts were not artificially inflated because of inconsistencies in spelling or transcription.

In keeping with the goal of examining growth in word use, rather than assumed vocabulary size, only word types produced in a given observation were counted. This decision was based on research suggesting considerable instability in children's early vocabulary production. For example, Bloom and Lahey (1978) showed that young children with 50-word vocabularies use a core set of these words frequently and others as rarely as once or twice in several months. Additionally, Rescorla (1980) found that 5\% of children's words between 12 and 20 months were not used for at least 2 months. It is unclear whether these words are still part of the child's productive vocabulary during such dormant periods, or whether the child in effect "forgets" the words and relearns them later. Given these uncertainties, as well as the relative dearth of longitudinal research examining growth in the variety of words children actually use, we opted to measure vocabulary production rather than assumed vocabulary size. We hypothesized that measuring growth in diversity of observed use might result in more linear growth than that documented earlier for cumulative vocabulary size, and indeed this hypothesis was confirmed.

Maternal input. The relationship between maternal communicative input (verbal and nonverbal) and growth in child vocabulary production was the primary interest in this study. The quantity of maternal verbal communication (total number of words produced, or word tokens), the diversity of vocabulary (number of different words produced, or word types), and the total number of pointing gestures used by the mothers during the interaction served as measures of maternal input. We found large variation in how much this sample of mothers talked and pointed during interaction with their children (Table 1), suggesting that the predictive power of these variables within a low-income sample was worthy of investigation. At each data-collection wave (14, 24, and 36 months), the relationship between mother tokens and mother types was strong ( $r s=.86-.90)$, whereas the relationship between mother points and mother types and tokens was moderate $(r s=.35-.54)$. It is important to keep in mind that none of the measures was completely independent of each other, as the number of types is a function of the number of tokens, and as most 
Table 1

Descriptive Statistics $(N=108)$

\begin{tabular}{lrrrr}
\hline & $M$ & $S D$ & Min & Max \\
\hline Child age in months at each wave & & & & \\
Wave 1 $(n=98)$ & 14.7 & 1.0 & 13.1 & 16.9 \\
Wave 2 $(n=82)$ & 25.0 & 1.7 & 22.7 & 32.4 \\
Wave 3 $(n=69)$ & 36.8 & 1.4 & 34.9 & 39.9 \\
Primary maternal predictors & & & & \\
Mother tokens & & & & \\
Wave 1 (child age $=14$ months) & 505.3 & 259.2 & 49 & 1,244 \\
Wave 2 (child age $=24$ months) & 629.3 & 234.1 & 163 & 1,294 \\
Wave 3 (child age $=36$ months) & 638.3 & 220.7 & 197 & 1,236 \\
Mother types & & & & \\
Wave 1 (child age $=14$ months) & 124.6 & 42.5 & 29 & 221 \\
Wave 2 (child age $=24$ months) & 164.0 & 45.7 & 74 & 320 \\
Wave 3 (child age $=36$ months) & 187.8 & 49.9 & 94 & 334 \\
Mother points & & & & \\
Wave 1 (child age $=14$ months) & 11.9 & 10.3 & 0 & 50 \\
Wave 2 (child age $=24$ months) & 12.9 & 9.4 & 0 & 42 \\
Wave 3 (child age $=36$ months) & 12.2 & 9.0 & 0 & 36 \\
Secondary maternal predictors & & & & \\
Maternal education (in years) & 11.8 & 1.4 & 8 & 18 \\
Vocabulary IQ (WAIS) & 36.7 & 13.3 & 12 & 66 \\
Literacy (WJ) & 50.6 & 5.2 & 28 & 57 \\
Depression (CES $-D)$ & 20.3 & 10.9 & 4 & 55 \\
\hline
\end{tabular}

Note. WAIS $=$ Wechsler Adult Intelligence Scale; WJ $=$ Woodcock Johnson Tests of Achievement; CES-D = Center for Epidemiologic Studies - Depression Scale.

pointing gestures did occur with speech. In this study we considered maternal input variables separately because we were interested in investigating the differing effects of tokens, types, and points; future research might consider using the variables together as a composite to gain an overall effect of maternal communicative input. We treated mother tokens, types, and points as time-varying predictors.

In addition to maternal communicative input, a secondary objective was to investigate the relationship between maternal predictors (i.e., education, language and literacy skills, depression) and child growth in vocabulary production. Information on the specific measures used follows.

Maternal education level. Data on education level were collected at baseline, reported in years. To facilitate interpretation of the individual growth parameters, education was centered at 12 years, a substantively interesting value that happens to be approximately the sample mean.

Maternal vocabulary and literacy skills. The vocabulary subscale of the Wechsler Adult Intelligence Scale-Revised (WAIS-R; Wechsler, 1981) and the letter-word identification portion of the Woodcock-Johnson Tests of Achievement (WJ; Woodcock,
1978) were administered to the mothers at baseline. The vocabulary subscale of the WAIS-R consists of 33 vocabulary words that participants are asked to define. The WJ letter-word identification test consists of 57 letters or words to be identified.

As expected, maternal vocabulary and literacy measures were related to one another $(r=.55$, $p<.0001)$. Therefore, they were standardized and combined using principal components analysis. We chose to use the first principal component, which weighted the variables equally and explained $77 \%$ of the total variance in the original two variables, as the one measure of language and literacy skills.

Maternal depression. The Center for Epidemiologic Studies-Depression (CES-D; Radloff, 1977) scale, on which adults rate on a 4-point scale the frequency with which they have recently experienced 20 depressive symptoms, was administered to mothers at baseline and at child ages 14, 24, and 36 months. Possible scores on the CES-D range from 0 to 60 . Scores between 16 and 20 indicate mild depression, scores between 21 and 26 indicate moderate depression, and scores over 26 indicate severe depression. The measure has also been shown to be valid in that it can distinguish psychiatric inpatient and general population samples, and scores on the CES$\mathrm{D}$ correlate positively with other self-report scales designed to measure depressive mood (Radloff, 1977). The average mother in this sample was mildly depressed at baseline, although the distribution of scores was positively skewed. On average, there was no change over time in depression levels (see also results of meta-analysis by Lovejoy et al., 2000, showing that depression effects endure over time). Because exploratory analysis in the current study suggested that the linearity assumption of the individual growth models was better met if the CES-D levels were transformed, the analyses presented here use the logarithm (to base 2) of the mother's CES-D scores at baseline. CES-D scores were imputed for 24 mothers based on regression estimates from models using as predictors the same mothers' baseline scores on the Child Abuse Potential (Milner, 1986) and depression subscale of the Parenting Stress Index (Abidin, 1995). Baseline scores were used because there was the least amount of missing data at that time point.

Controls. Child gender (dummy variable $=$ male), child birth order (dummy variable = firstborn), maternal age, family income, and family participation in EHS served as control variables, based on the previous literature highlighting their importance and on issues integral to study design. In the sample examined here, $48 \%$ of the children were firstborn and 
$50 \%$ were male. The average maternal age at baseline was 25.5 years, and the average yearly gross family income (as reported by the mother at baseline) was $\$ 11,237$. Fifty-one percent of the sample was in the EHS program group.

\section{Results}

\section{Descriptive Statistics of Observed Data}

The distribution of observed child vocabulary production at each age is presented in Figure 1b. As mentioned earlier, these estimates are an index of child vocabulary use, not estimates of total vocabulary knowledge. Children's use of vocabulary during these 10-min interactions varied both within and across ages. Looking first within ages, variability in the number of different words children produced increased substantially with child age. For example, the range of word types produced was 22 types at 14 months, 95 types at 24 months, and 122 types at 36 months. The 14-month-olds produced a median of 1 intelligible word, whereas the 36-month-olds produced a median of 76 words. On average, at 14 months these children were at the very beginning of expressive vocabulary development. Finally, for comparison with earlier work by Huttenlocher et al. (1991), we provide mean, median, and standard deviations for cumulative word types at 24 and 36 months. For the 57 children for whom data were available at all three time points, the mean cumulative word types at 24 months (i.e., types including those produced at 14 but not again at 24 months) was $35.7(M d n=34, S D=26)$; the mean cumulative words types at 36 months was 97.1 $(M d n=101$, $S D=37.8$ ). Number of observed word types (those the child actually produced) and cumulative word types (observed plus those produced earlier) were highly correlated $(r=.99, p<.001$ at 24 months, and $r=.93, p<.001$ at 36 months). For this sample, the cumulative approach yielded very similar estimations at 24 months, but on average approximately $33 \%$ more word types at 36 months.

\section{Developing a Multilevel Model of Vocabulary Growth}

Individual growth modeling techniques were used to analyze the longitudinal data. All analyses were conducted using SAS PROC MIXED, full maximum likelihood method. The multilevel model for change allowed us to address simultaneously both research questions: (a) the Level 1 (within-person) question focused on individual change over time in vocabulary production, and (b) the Level 2 (between-person) question focused on how these individual changes vary across families (Singer \& Willett, 2003). To develop an appropriate Level 1 model to describe the growth rates of individual children, we first examined the empirical growth trajectories for all 108 children over time. Visual inspection of these trajectories (presented in Figure 1c) indicated a fair amount of variation in both the rate and shape of the trajectory: Although some trajectories appeared roughly linear, many others were markedly curvilinear (with the rate of growth increasing with child age). To ensure that the postulated Level 1 model appropriately captured both types of variation we moved quickly from a linear Level 1 specification to comparatively examining various curvilinear forms (including quadratic and logarithmic specifications). After exploring a wide range of possibilities, we found that the best fitting Level 1 specification (i.e., the model with the lowest value on the -2 log-likelihood [-2LL] and Akaike information criterion [AIC] statistics) included both linear and quadratic components:

$$
\begin{aligned}
\text { CHILD TYPES }_{i t}= & \pi_{0 i}+\pi_{1 i}(\mathrm{AGE}-14)_{i t} \\
& +\pi_{2 i}(\mathrm{AGE}-14)_{i t}^{2}+\varepsilon_{i t}
\end{aligned}
$$

In Equation 1, CHILD TYPES ${ }_{i t}$ represents the vocabulary production for child $i$ at time $t$. By centering child age around 14 months, ${ }^{2}$ the individual growth parameters have the following interpretations: $\pi_{0 i}$ represents child $i$ 's true level of vocabulary production at 14 months, $\pi_{1 i}$ represents child $i$ 's true instantaneous rate of growth at 14 months, and $\pi_{2 i}$ represents child $i$ 's quadratic acceleration in growth over time. The residual in Equation 1, $\varepsilon_{i t}$, represents that portion of child $i$ 's vocabulary production at age $t$ that is not predicted by his or her age.

The between-person portion of the multilevel model for change (Level 2) used the individual growth parameters from the within-person (Level 1) model as outcomes and enabled us to determine whether children vary in their initial status, instantaneous rates of change, or acceleration, and if so, what predicted that variation (see the Appendix for full description of the derivation of the multilevel model). A major advantage of the individual growth modeling approach is that it allowed us to examine the effects of predictors that are time invariant (such as maternal education, language and literacy, depression, and controls, as treated in this study) as well as the effects of predictors that are time varying (such as mother tokens, mother types, and mother points). Because the individual growth modeling approach relies on a person-period data set, each 
predictor can, if appropriate, take on a specific value for each measurement occasion. The values of timeinvariant predictors (e.g., child gender) are constant across the multiple records in the person-period data set. However, the values of time-varying predictors (such as maternal types) are allowed to take on the specific values they have at each measurement occasion. A complete explanation of how this works operationally is given in Singer and Willett (2003).

Table 2 presents the results of model building. Model 1, the unconditional means model, has no predictors and primarily serves as a baseline for model comparison. Model 2 presents the results of fitting the unconditional growth model (see the Appendix). The fixed effects for the intercept, linear, and quadratic terms are all positive and statistically significant. We estimate that the average child spoke approximately 1 word at age 14 months (1.08), that the child's rate of increase in vocabulary acquisition at this age was just over 2 words per month (2.37), and that over time the rate of increase in vocabulary acquisition itself increased. As we would expect, child age is a good predictor of growth in child vocabulary production. Figure 2 displays the average fitted growth trajectory based on Model 2.

Thus, to answer the first research question, average growth in vocabulary production among this sample of children from low-income families was fairly linear with a slight increase in upward curvature between 1 and 3 years of age. The average child's production increased from an estimated 1.1 word types at 14 months to 27.8 word types at 24 months to 67.7 word types at 36 months.

\section{Predicting Growth in Vocabulary Production}

To answer the second research question, potential predictors of growth in vocabulary production were grouped into three categories: (a) priority predictors (maternal verbal and nonverbal input), (b) secondary predictors (maternal education, maternal literacy skills, and maternal depression), and (c) controls (child gender, child birth order, maternal age, family income, and EHS program status). Given that participation in the EHS program was a design variable, we began by looking at the uncontrolled effect of EHS. Next, we fit a series of models investigating the role of maternal input (types, tokens, and pointing gestures). Then, we explored the relationship between secondary predictors and child vocabulary growth, followed by an examination of the role of control predictors. As a last step, we combined all significant predictors in one final model predicting growth in child vocabulary production.
Preliminary analysis revealed no discernible effect of program status on growth in child language production. We were surprised by this result, given that the larger national EHS study did find significant program effects on child language development (Love et al., 2002) when language skills were measured using standardized tests such as the Bayley Scales of Infant Development (Bayley, 1993). In addition, in the current sample, we did observe significant group differences in child word types at 24 months, though not at 14 or 36 months. Nonetheless, given that program status had a null effect on growth rate of vocabulary production considered over the entire 2-year period between 14 and 36 months (and on initial production of word types at 14 months), we dropped program status as a control variable in subsequent analyses.

\section{Effect of Maternal Input on Growth in Child Vocabulary Production}

Models 3 through 6 in Table 2 present a taxonomy investigating the relationship between maternal communicative input and growth in child vocabulary production. Model 3 shows the effect of timevarying maternal tokens, Model 4 shows the effect of time-varying maternal types, and Model 5 shows the effect of time-varying maternal pointing gestures on initial status and growth in child vocabulary production.

As expected, none of these predictors had a significant main effect on the intercept. Neither was there any effect of maternal tokens on growth in child vocabulary production (Model 3). Goodnessof-fit statistics and the nonsignificant parameter estimates indicated no reason to retain maternal tokens in further models. Models 4 and 5, however, suggested significant effects of diversity of maternal vocabulary (i.e., mother word types) and number of pointing gestures on growth in child vocabulary production. Comparisons of the goodness-of-fit statistics between Model 2 containing just child age and Model 4 containing mother types (nested models) revealed a modest, but insignificant, change in the $-2 \mathrm{LL}$ statistic of $4.5(d f=3, p>.05)$. Similarly, comparing Model 2 and Model 5, which included mother pointing, revealed a modest yet nonsignificant change in deviance of $3.8(d f=3, p>.05)$. However, the significant individual parameter estimates $(p<.05)$ for the effects of both maternal types and maternal pointing on child vocabulary growth led us to explore further the effects of these two predictors. When both were considered simultaneously (model not shown), the two predictors appeared 
Table 2

Estimates of Fixed and Random Effects From a Series of Individual Growth Models in Which Maternal Input (Tokens, Types, and Points) Predict the Average Child Vocabulary Production at 14 Months and Linear and Quadratic Rate of Change (Simultaneously) in Child Vocabulary Between 14 and 36 months $(N=108)$

\begin{tabular}{|c|c|c|c|c|c|c|}
\hline & \multicolumn{6}{|c|}{ Parameter estimate (SE) Child word types } \\
\hline & Model 1 & Model 2 & Model 3 & Model 4 & Model 5 & Model 6 \\
\hline \multicolumn{7}{|l|}{ Fixed effects } \\
\hline Intercept & $\begin{array}{l}2.48^{* * * *} \\
(0.43)\end{array}$ & $\begin{array}{c}1.08^{*} \\
(0.43)\end{array}$ & $\begin{array}{l}1.87^{*} \\
(.09)\end{array}$ & $\begin{array}{c}2.04 \\
(1.29)\end{array}$ & $\begin{array}{c}1.82^{*} \\
(0.70)\end{array}$ & $\begin{array}{l}1.26^{* *} \\
(0.43)\end{array}$ \\
\hline Age (centered) & & $\begin{array}{l}2.37^{* * *} \\
(0.32)\end{array}$ & $\begin{array}{l}1.74^{*} \\
(0.80)\end{array}$ & $\begin{array}{c}0.35 \\
(1.01)\end{array}$ & $\begin{array}{l}1.61^{* *} \\
(0.54)\end{array}$ & $\begin{array}{c}0.56 \\
(0.96)\end{array}$ \\
\hline $\operatorname{Age}^{2}$ (centered) & & $\begin{array}{c}0.03^{*} \\
(0.01)\end{array}$ & $\begin{array}{c}0.06^{\dagger} \\
(0.04)\end{array}$ & $\begin{array}{l}0.13^{* *} \\
(0.05)\end{array}$ & $\begin{array}{c}0.07^{*} \\
(0.03)\end{array}$ & $\begin{array}{l}0.12^{* *} \\
(0.01)\end{array}$ \\
\hline Mother tokens & & & $\begin{array}{r}-0.001 \\
(0.002)\end{array}$ & & & \\
\hline Mother Tokens $\times$ Age & & & $\begin{array}{c}0.001 \\
(0.001)\end{array}$ & & & \\
\hline Mother Tokens $\times$ Age $^{2}$ & & & $\begin{array}{r}-0.000 \\
(0.000)\end{array}$ & & & \\
\hline Mother word types & & & & $\begin{array}{r}-0.006 \\
(0.009)\end{array}$ & & \\
\hline Mother Word Types $\times$ Age & & & & $\begin{array}{c}0.014^{*} \\
(0.007)\end{array}$ & & $\begin{array}{c}0.012^{*} \\
(0.006)\end{array}$ \\
\hline Mother Word Types $\times$ Age $^{2}$ & & & & $\begin{array}{c}-0.001^{*} \\
(0.000)\end{array}$ & & $\begin{array}{c}-0.001^{*} \\
(0.000)\end{array}$ \\
\hline Mother points & & & & & $\begin{array}{r}-0.06 \\
(0.04)\end{array}$ & \\
\hline Mother Points $\times$ Age & & & & & $\begin{array}{c}0.07^{*} \\
(0.04)\end{array}$ & \\
\hline Mother Points $\times \mathrm{Age}^{2}$ & & & & & $\begin{array}{r}-0.004^{*} \\
(0.002)\end{array}$ & \\
\hline \multicolumn{7}{|l|}{ Random effects } \\
\hline Level 1: Time 1 & $\begin{array}{l}17.81^{* * *} \\
(2.55)\end{array}$ & $\begin{array}{l}14.76^{* * *} \\
(2.57)\end{array}$ & $\begin{array}{l}14.73^{* * *} \\
(2.45)\end{array}$ & $\begin{array}{l}14.31^{* * *} \\
(2.45)\end{array}$ & $\begin{array}{l}15.53^{* * *} \\
(2.71)\end{array}$ & $\begin{array}{l}14.42^{* * *} \\
(2.47)\end{array}$ \\
\hline Level 1: Time 2 & $\begin{array}{l}1,784.62^{* * *} \\
(274.29)\end{array}$ & $\begin{array}{l}566.82^{* * *} \\
(111.03)\end{array}$ & $\begin{array}{l}551.77^{* * *} \\
(110.26)\end{array}$ & $\begin{array}{l}530.89^{* * *} \\
(106.22)\end{array}$ & $\begin{array}{l}520.96^{* * *} \\
(106.38)\end{array}$ & $\begin{array}{l}534.96^{* * *} \\
(106.66)\end{array}$ \\
\hline Level 1: Time 3 & $\begin{array}{l}6,095.77^{* * *} \\
(977.51)\end{array}$ & $\begin{array}{c}335.18^{\dagger} \\
(206.27)\end{array}$ & $\begin{array}{r}326.77^{\dagger} \\
(205.53)\end{array}$ & $\begin{array}{r}319.02^{\dagger} \\
(203.97)\end{array}$ & $\begin{array}{c}349.02^{*} \\
(207.03)\end{array}$ & $\begin{array}{r}333.59^{\dagger} \\
(204.96)\end{array}$ \\
\hline Level 2: Slope (linear) & & $\begin{array}{c}0.79 * \\
(0.42)\end{array}$ & $\begin{array}{c}0.81^{*} \\
(0.42)\end{array}$ & $\begin{array}{c}0.84^{*} \\
(0.42)\end{array}$ & $\begin{array}{c}0.76^{*} \\
(0.41)\end{array}$ & $\begin{array}{c}0.81^{*} \\
(0.42)\end{array}$ \\
\hline \multicolumn{7}{|l|}{ Goodness of fit } \\
\hline$-2 \mathrm{LL}$ & $2,116.0$ & $1,932.9$ & $1,931.6$ & $1,928.4$ & $1,929.1$ & $1,928.8$ \\
\hline AIC & $2,130.0$ & $1,952.9$ & $1,957.6$ & $1,954.4$ & $1,955.1$ & $1,952.8$ \\
\hline
\end{tabular}

Note. Model 1 is an unconditional means model. Model 2 is an unconditional growth model. Model 3 adds the main effect of mother tokens as well as the Mother Tokens $\times$ Age and Mother Tokens $\times$ Age $^{2}$ interaction effects. Model 4 builds on Model 2 by adding the main effect of mother types as well as the Mother Types $\times$ Age and Mother Types $\times$ Age $^{2}$ interaction effects. Model 5 builds on Model 2 by adding the main effect of mother points as well as the Mother Points $\times$ Age and Mother Points $\times$ Age $^{2}$ interaction effects. Model 6 shows the Mother Types $\times$ Age and Mother Types $\times$ Age $^{2}$ interaction effects; this model is the most parsimonious model fit using maternal input variables to explain growth in child vocabulary production. $-2 \mathrm{LL}=-2 \log$-likelihood; AIC $=$ Akaike information criterion. Covariances are not presented but were also estimated and are available on request. p $p<.10 .{ }^{*} p<.05 .{ }^{* *} p<.01 .{ }^{* * *} p<.001$.

to be collinear (i.e., neither was statistically significant). Thus, we chose to retain mother word types as the maternal input predictor of interest in subsequent analyses.
In Model 6, we removed the nonsignificant main effect of mother word types on the intercept term and fit a model with the effect of mother word types on growth in child vocabulary production. This 


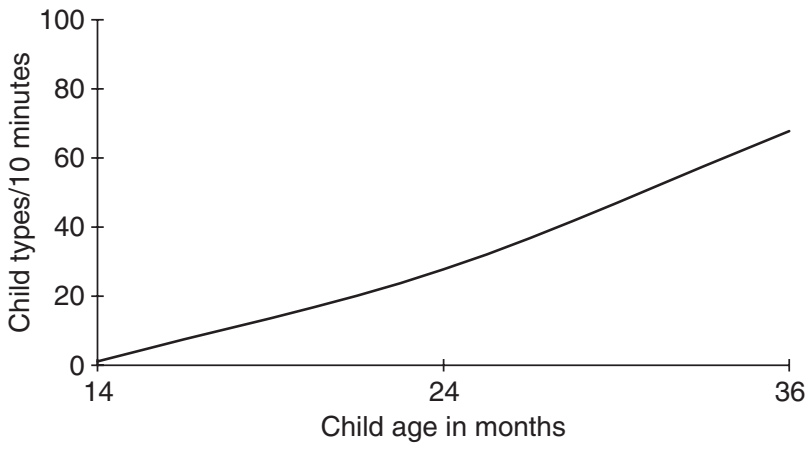

Figure 2. Average growth in child vocabulary production from 14 to 36 months $(N=108)$.

model fit slightly better than Model 4 also containing the main effect term (based on similar -2LL statistic and lower AIC statistic). The negative parameter estimate for the effect of mother word types on curvature indicates that growth slowed over time. We concluded that Model 6, containing the effect of mother word types on instantaneous growth and curvature, was the most parsimonious model we could fit to the data using maternal input variables to explain growth in child vocabulary production.

Results indicated that children whose mothers consistently used more varied vocabulary had faster, more linear growth between 14 and 36 months than children whose mothers consistently used less varied vocabulary. Figure 3a presents prototypical growth trajectories based on Model 6 to demonstrate these findings. For illustrative purposes in this and subsequent graphs, we defined "hi" as the 90th percentile and " $1 \mathrm{o}^{\text {" }}$ as the 10th percentile based on univariates of the relevant time-varying predictor. The 90th percentile for mother word types was 221 types; the 10th percentile was 87 word types. The gap between the children of hi type versus lo type mothers was largest at 24 months, during the earlier stages of vocabulary acquisition. For example, at 24 months, a child whose mother consistently used diverse vocabulary had an estimated productive vocabulary of 33.5 word types for the 10-min interaction, whereas a child whose mother consistently produced talk with little lexical diversity had an estimated productive vocabulary of 24.5 word types. By 36 months the effect of maternal types had dissipated, such that the vocabulary production of children of mothers who used many types was indistinguishable from that of children whose mothers used fewer word types: The difference of 9 word types in children's production had shrunk to approximately 1 word type. Therefore, the effect of maternal types on child vocabulary production appears particularly pronounced during the early
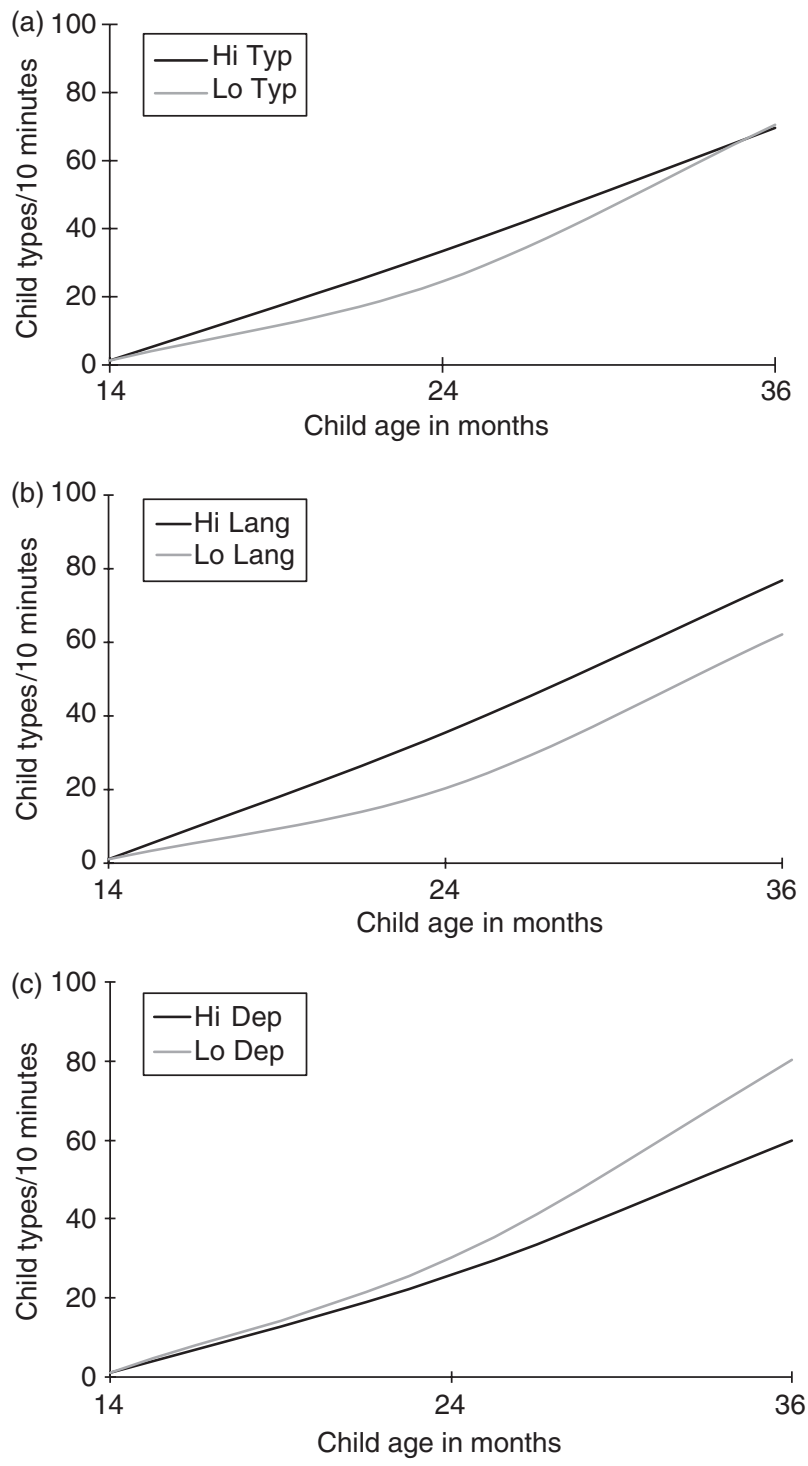

Figure 3. (a) Effect of time-varying maternal word types on growth in child vocabulary production $(N=108)$. Hi typ $=$ estimated word types per $10 \mathrm{~min}$ for children of mothers who consistently scored at the 90th percentile of mother word types. Lo typ $=$ estimated word types for children of mothers who consistently scored at the 10th percentile of mother word types. (b) Effect of maternal language and literacy on growth in child vocabulary production $(N=108)$. Hi lang = estimated word types per $10 \mathrm{~min}$ for children of mothers who scored at the 90th percentile on the language and literacy composite. Lo lang = estimated word types for children of mothers who scored at the 10th percentile on the language and literacy composite. (c) Effect of maternal depression on growth in child vocabulary production $(N=108)$. Hi dep $=$ estimated word types per $10 \mathrm{~min}$ for children of mothers who scored at the 90th percentile on the Center for Epidemiologic Studies-Depression Scale (CES-D). Lo Dep = estimated word types for children of mothers who scored at the 10th percentile on the CES-D.

stages of language development, around 24 months of age. The effect of maternal pointing was also particularly salient during this same period. 
Table 3

Estimates of Fixed and Random Effects From a Series of Individual Growth Models in Which Maternal Types, Language and Literacy, and Depression Predict the Linear and Quadratic Rate of Change (Simultaneously) in Child Vocabulary Between 14 and 36 Months $(N=108$

\begin{tabular}{|c|c|c|c|c|c|c|c|}
\hline & \multicolumn{7}{|c|}{ Parameter estimate (SE) Child word types } \\
\hline & Model 1 & Model 2 & Model 3 & Model 4 & Model 5 & Model 6 & Model 7 \\
\hline \multicolumn{8}{|l|}{ Fixed effects } \\
\hline Intercept & $\begin{array}{l}2.48^{* * *} \\
(0.43)\end{array}$ & $\begin{array}{c}1.08^{*} \\
(0.43)\end{array}$ & $\begin{array}{l}1.26^{* *} \\
(0.43)\end{array}$ & $\begin{array}{c}1.05^{*} \\
(0.44)\end{array}$ & $\begin{array}{c}1.08^{*} \\
(0.43)\end{array}$ & $\begin{array}{c}1.05^{*} \\
(0.44)\end{array}$ & $\begin{array}{l}1.28^{* *} \\
(0.44)\end{array}$ \\
\hline Age (centered) & & $\begin{array}{l}2.37^{* * *} \\
(0.32)\end{array}$ & $\begin{array}{c}0.56 \\
(0.96)\end{array}$ & $\begin{array}{l}2.42^{* * *} \\
(0.32)\end{array}$ & $\begin{array}{l}2.35^{* * *} \\
(0.32)\end{array}$ & $\begin{array}{l}2.40^{* * *} \\
(0.32)\end{array}$ & $\begin{array}{c}0.45 \\
(0.96)\end{array}$ \\
\hline $\operatorname{Age}^{2}$ (centered) & & $\begin{array}{c}0.03^{*} \\
(0.01)\end{array}$ & $\begin{array}{l}0.12^{* *} \\
(0.01)\end{array}$ & $\begin{array}{c}0.03^{*} \\
(0.01)\end{array}$ & $\begin{array}{l}0.11^{* * *} \\
(0.03)\end{array}$ & $\begin{array}{l}0.11^{* * *} \\
(0.03)\end{array}$ & $\begin{array}{l}0.23^{* * *} \\
(0.06)\end{array}$ \\
\hline Mother Word Types $\times$ Age & & & $\begin{array}{c}0.012^{*} \\
(0.006)\end{array}$ & & & & $\begin{array}{c}0.01^{*} \\
(0.01)\end{array}$ \\
\hline Mother Word Types $\times$ Age $^{2}$ & & & $\begin{array}{r}-0.001^{*} \\
(0.000)\end{array}$ & & & & $\begin{array}{r}-0.00^{*} \\
(0.00)\end{array}$ \\
\hline Language/ Literacy $\times$ Age & & & & $\begin{array}{c}0.66^{*} \\
(0.27)\end{array}$ & & $\begin{array}{c}0.64^{*} \\
(0.27)\end{array}$ & $\begin{array}{c}0.22^{*} \\
(0.10)\end{array}$ \\
\hline Language/ Literacy $\times \mathrm{Age}^{2}$ & & & & $\begin{array}{r}-0.02^{\dagger} \\
(0.01)\end{array}$ & & $\begin{array}{r}-0.02^{\dagger} \\
(0.01)\end{array}$ & \\
\hline Depression $\times$ Age $^{2}$ & & & & & $\begin{array}{c}-0.02^{* *} \\
(0.01)\end{array}$ & $\begin{array}{c}-0.00^{* *} \\
(0.01)\end{array}$ & $\begin{array}{l}-.02^{* *} \\
(0.01)\end{array}$ \\
\hline \multicolumn{8}{|l|}{ Random effects } \\
\hline Level 1: Time 1 & $\begin{array}{l}17.81^{* * *} \\
(2.55)\end{array}$ & $\begin{array}{l}14.76^{* * *} \\
(2.57)\end{array}$ & $\begin{array}{l}14.42^{* * *} \\
(2.47)\end{array}$ & $\begin{array}{l}15.33^{* * *} \\
(2.64)\end{array}$ & $\begin{array}{l}15.16^{* * *} \\
(2.64)\end{array}$ & $\begin{array}{l}15.62^{* * *} \\
(2.69)\end{array}$ & $\begin{array}{l}14.86^{* * *} \\
(2.54)\end{array}$ \\
\hline Level 1: Time 2 & $\begin{array}{l}1,784.62^{* * *} \\
(274.29)\end{array}$ & $\begin{array}{l}566.8^{* * *} \\
(111.03)\end{array}$ & $\begin{array}{l}535.0^{* * *} \\
(106.66)\end{array}$ & $\begin{array}{l}501.7^{* * *} \\
(101.25)\end{array}$ & $\begin{array}{l}567.3^{* * *} \\
(109.34)\end{array}$ & $\begin{array}{l}506.3^{* * *} \\
(100.36)\end{array}$ & $\begin{array}{l}499.4^{* * *} \\
(99.18)\end{array}$ \\
\hline Level 1: Time 3 & $\begin{array}{l}6,095.77^{* * *} \\
(977.51)\end{array}$ & $\begin{array}{r}335.18^{\dagger} \\
(206.27)\end{array}$ & $\begin{array}{l}333.59- \\
(204.96)\end{array}$ & $\begin{array}{c}333.56^{*} \\
(201.88)\end{array}$ & $\begin{array}{r}342.37^{\dagger} \\
(205.72)\end{array}$ & $\begin{array}{c}345.87^{*} \\
(201.76)\end{array}$ & $\begin{array}{c}314.47^{\dagger} \\
(196.49)\end{array}$ \\
\hline Level 2: Slope (linear) & & $\begin{array}{c}0.79^{*} \\
(0.42)\end{array}$ & $\begin{array}{c}0.81^{*} \\
(0.42)\end{array}$ & $\begin{array}{c}0.71^{*} \\
(0.40)\end{array}$ & $\begin{array}{c}0.61^{\dagger} \\
(0.41)\end{array}$ & $\begin{array}{r}0.56^{\dagger} \\
(0.39)\end{array}$ & $\begin{array}{l}0.61 \sim \\
(0.40)\end{array}$ \\
\hline \multicolumn{8}{|l|}{ Goodness of fit } \\
\hline$-2 \mathrm{LL}$ & $2,116.0$ & $1,932.9$ & $1,928.8$ & $1,926.0$ & $1,925.5$ & $1,919.4$ & $1,915.8$ \\
\hline AIC & $2,130.0$ & $1,952.9$ & $1,952.8$ & $1,950.0$ & $1,947.5$ & $1,945.4$ & $1,943.8$ \\
\hline
\end{tabular}

Note. Model 1 is an unconditional means model. Model 2 is an unconditional growth model. Model 3 is the same as Model 6 from Table 2 showing the Mother Word Types $\times$ Age interaction effect. Model 4 displays the Language/Literacy $\times$ Age and Language/Literacy $\times$ $\mathrm{Age}^{2}$ interaction effects. Model 5 shows the Depression $\times \mathrm{Age}^{2}$ interaction effect. Model 6 shows the Language/Literacy $\times$ Age and Language/Literacy $\times \mathrm{Age}^{2}$ interaction effects combined with the Depression $\times \mathrm{Age}^{2}$ interaction effect. Model 7 is the final model for explaining change over time in child vocabulary production and includes the Mother Word Types $\times$ Age, Mother Word Types $\times$ Age $^{2}$, Language/Literacy $\times$ Age, and Depression $\times \mathrm{Age}^{2}$ interaction effects. $-2 \mathrm{LL}=-2$ log-likelihood; AIC $=$ Akaike information criterion. Covariances are not presented but were also estimated and are available on request.

${ }^{\dagger} p<.10 .{ }^{*} p<.05 .{ }^{* *} p<.01 .{ }^{* * *} p<.001$.

\section{Effect of Secondary Predictors and Controls on Child Vocabulary Growth}

The final set of analyses examined the effects of maternal lexical diversity (word types) on child growth when other maternal and child factors were also considered. As in the previous analysis, a taxonomy of models was fit examining the effects of maternal education, language and literacy skills, and depression. Although none of these variables had an effect on initial status of child vocabulary production, education and language and literacy were both predictors of linear $(p<.05)$ and quadratic growth $(p<.07)$.
When combined in the same model, these two predictors appeared collinear, leading us to retain only the significant effect of language and literacy on growth in child vocabulary production (see Model 4, Table 3).

The effect of maternal language and literacy on growth in child vocabulary production is displayed in Figure 3b. At 24 months a child whose mother scored at the 90th percentile on the language and literacy composite produced approximately 15 more word types than a child whose mother scored at the 10th percentile of the language and literacy composite. The difference was of similar magnitude at child age 36 months. 
Maternal depression status at study entry was also related to curvature in child growth $(p<.01$; see Model 5, Table 3). This effect is displayed in Figure $3 c$, showing that at age 24 months a child whose mother scored in the 90th percentile for this sample on the CES-D produced approximately 4 fewer word types than a child whose mother scored at the 10th percentile. By 36 months this differential had grown to approximately 20 word types. Thus, the effect of maternal depression on child vocabulary production was more evident during the latter part of the 2-year study period.

A comparison of goodness-of-fit statistics and parameter estimates for the secondary predictors in the models shown in Table 3 indicates that the best fitting model was one that included the effects of maternal language and literacy on child instantaneous growth and curvature and the effects of maternal depression on curvature in child vocabulary production (Model 6 in Table 3).

Similar analysis of the role of the control predictors (maternal age, child gender, child birth order, and a $\log$ base 2 version of family income, because of skewed distribution of values) showed that none had an effect on initial status. In addition, maternal age, child gender, family income, and birth order each had no effect on growth in child vocabulary production. Thus, these factors were not included in further models.

As the final step, mother word types, maternal language and literacy, and maternal depression were all included in the same model to investigate their simultaneous effects. All predictors remained significant, with the exception of the effect of language and literacy on quadratic growth. The final model, then, included the effect of mother word types on instantaneous rate of change and curvature, the effect of language and literacy on instantaneous rate of change, and the effect of depression on curvature (see Model 7, Table 3). Despite three outlier intercept residuals due to the few children with large productive vocabularies at 14 months, no model assumptions were violated. The fixed effects from this model indicate that, after controlling for maternal literacy skills and depression, $1 S D$ difference in the number of maternal word types directed to the child over time was positively associated with a .01 word difference per month in the child's instantaneous growth rate $(p<.05)$, and a -.001 word per month squared difference in the curvature $(p<.05)$. In addition, after controlling for depression and maternal types, $1 S D$ difference on the maternal language and literacy composite score was positively associated with a .22 word difference per month in the instan- taneous growth rate $(p<.05)$. Finally, controlling for maternal types and maternal literacy skills, $1 S D$ difference on the depression composite was negatively associated with a .02 word difference per month squared $(p<.01)$.

A more complete picture of the magnitude of the effect of the predictors can be seen in Figure 4, which displays the combined effect of maternal types, maternal depression, and maternal literacy on growth in child vocabulary production. Given the absence of main effects of the predictors on the intercept terms, all children began with the same value of child vocabulary production at 14 months (1.3 word types).

The estimated trajectories of growth in vocabulary production for four prototypical groups of children, chosen to display the differing effects of input, maternal verbal ability, and maternal depression, are shown in Figure 4. The first group (displayed as solid black line) includes children whose mothers consistently used many word types during interaction, had high language and literacy skills, and had low levels of depression at the time they entered the study. These are children one would expect to develop at a rapid and consistent rate across time, an expectation that is borne out by their average trajectory. The second group, whose growth rates were steady across time (the dashed gray line), is composed of children whose mothers consistently used many word types despite low language and literacy skills and high levels of depression at study entry. These children's growth rates are consistently slow across the study period despite relatively rich lexical input from their mothers.

Two groups of children showed more curvilinear growth. One group (the dashed black line) included children whose mothers had high language and literacy skills and low levels of depression but consistently used low levels of lexical diversity. Although these children's rate of growth was initially slower than that of children whose mothers had similar verbal ability and mental health status but who provided richer input, the children demonstrated something of a rebound effect in growth rate after age 24 months.

The other group of children demonstrating markedly curvilinear growth (the solid gray line) was composed of children whose mothers consistently used few word types during interaction, had low language and literacy skills, and had high levels of depression at the time of study entry. These are children one might predict to have slow, consistent growth across time. In fact, however, they too show some acceleration in growth rate beginning around age 24 months. 


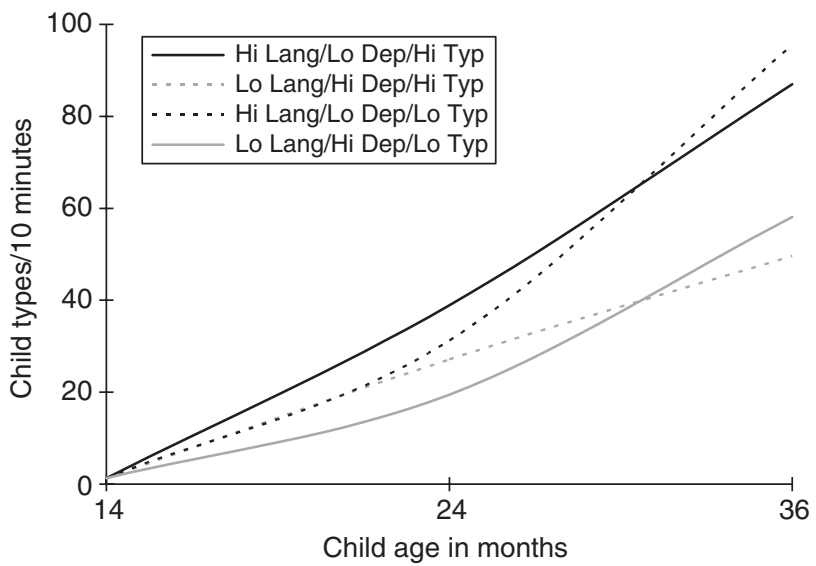

Figure 4. Effect of maternal word types, maternal language and literacy skills, and maternal depression on growth in child vocabulary production $(N=108)$. Solid black line represents the estimated growth in child word types per $10 \mathrm{~min}$ for children whose mothers used many word types during interaction (90th percentile), had high language and literacy skills (90th percentile), and had low levels of depression at study entry (10th percentile). Dashed gray line represents the estimated growth in child word types per $10 \mathrm{~min}$ for children whose mothers used many word types during interaction (90th percentile), had low language and literacy skills (10th percentile), and had high levels of depression at study entry (90th percentile). Dashed black line represents the estimated growth in child word types per $10 \mathrm{~min}$ for children whose mothers used few word types during interaction (10th percentile), had high language and literacy skills (90th percentile), and had low levels of depression at study entry (10th percentile). Solid gray line represents the estimated growth in child word types per $10 \mathrm{~min}$ for children whose mothers used few word types during interaction (10th percentile), had low language and literacy skills (10th percentile), and had high levels of depression at study entry (90th percentile).

As one might expect, comparing the two groups represented by solid lines, we see that children of mothers who consistently produced many word types during interaction, had high language and literacy skills, and had low levels of depression upon joining the study had higher estimated productive vocabularies between 14 and 36 months than peers whose mothers produced few word types, had lower language and literacy skills, and had higher levels of depression. The estimated average number of word types produced in $10 \mathrm{~min}$ by children in the former group was approximately 39 word types at 24 months, compared with 19 word types for a child in the latter group. This large differential continued at 36 months, with an estimated average productive vocabulary per $10 \mathrm{~min}$ of 87 word types for children in the former group and 58 word types for children in the latter group.

Comparing the two groups of children of mothers with high language and literacy skills and low levels of depression (the solid and dashed black lines) shows us that the positive effect of maternal types is stronger during the earliest years of language learning. Children in the group whose mothers consistently provided rich lexical input over the study period enjoyed an advantage of approximately eight word types in their estimated average word types per $10 \mathrm{~min}$ at 24 months over the children of mothers with similarly high verbal skills and mental health status who provided consistently poorer lexical input. However, by 36 months, children in the latter group had caught up with and surpassed by an estimated eight word types those in the former group. We see similar results when comparing children represented by the solid and dashed gray lines, with the effect of mother types providing an advantage up through 2 years of age that is less marked by 3 years of age.

Finally, if we compare the children in groups represented by the two dashed lines, the stronger effect of maternal language and literacy and depression and the waning influence of maternal lexical diversity in later toddlerhood become evident. These results suggest that the effect of maternal word types is particularly strong during the infant and toddler years but begins to be overshadowed by the effect of maternal language and literacy skills and depression as children near age 3 years. These changing patterns show the importance of examining the potentially variable effects of factors across early development.

In sum, the results of this study demonstrate considerable variability in the rate and shape of growth in vocabulary production among children from low-income families over the infant and toddler years. In addition to the expected effect of child age, several maternal factors studied here help explain the observed variability. These factors include maternal behavior (i.e., diversity of vocabulary addressed to the child during free-play interaction), maternal knowledge (i.e., language and literacy skills measured on standardized tests when the child was less than 1 year old), and maternal mental state (i.e., depression measured when the child was less than 1 year old).

\section{Discussion}

The results of this study complement earlier research in several important ways. First, this description of growth in children's observed vocabulary use across the first 3 years of life complements earlier studies that examined growth in children's cumulative vo- 
cabulary size (Hart \& Risley, 1995; Huttenlocher et al., 1991). The current study also helps address the serious dearth of observational data on children from other than middle-class and professional families. Finally, the sample of 108 children studied here is considerably larger than those in most previous longitudinal studies of observed vocabulary production in infants and toddlers (Bornstein, TamisLeMonda, \& Haynes, 1999; Tamis-LeMonda, Bornstein, \& Baumwell, 2001). Thus, the predictors of variation examined here allow comparison with earlier research on growth in cumulative vocabulary size in smaller samples of children from middle-class families. In addition, however, the current study includes examination of the potential effect of one type of nonverbal input, maternal pointing.

Although the purpose of this study was not to compare children in this sample with children from more advantaged backgrounds, we should perhaps note that the children on average appear to begin lagging behind their middle-class peers in vocabulary production by age 3 . For example, at approximately 36 months of age, children in the current sample produced an average of 73 word types in 10 min of mother-child interaction, compared with 84 words produced by 32-month-old children from working- and middle-class families in an earlier study using a similar protocol (Pan, Snow, \& Willett, 1993). Samples in the two studies were similar in ethnicity and home language background, but differed in socioeconomic status (SES) and residence (rural vs. urban Northeastern United States). These group differences in vocabulary skill across children from different SES backgrounds are consistent with the results of many other studies in the research literature (e.g., Hart \& Risley, 1995; Hoff-Ginsberg, 1998). What is perhaps more notable and more directly related to the purpose of this study, however, is that the variation around the means in the two samples was similar $(S D=26.8$ in the higher SES sample vs. 27.2 in the lower SES sample). Thus, the central questions in the current study had to do with factors associated with the variation in the vocabulary production observed.

We examined the effects of three maternal communicative input predictors - word tokens, word types, and pointing - on growth in children's vocabulary production during the first 3 years of life. Despite the strong relationship between maternal tokens and types, we were interested in whether each predictor had the same effect on growth in vocabulary production when considered on its own. In addition, we were interested in what, if any, effect nonverbal input had on children's vocabulary growth.
We found that diversity of maternal vocabulary (word types) directed to children predicted growth in child vocabulary production and that this effect was particularly strong around children's second birthday. In this sample, maternal word types were a stronger predictor of growth in child vocabulary production than was maternal talkativeness. In fact, maternal talkativeness, while positively associated with maternal word types, did not have any independent effect on growth in vocabulary production, a surprising result considering findings from studies with middle-class (Huttenlocher et al., 1991) and mixed-class (Hart \& Risley, 1995) samples showing a relationship between maternal talkativeness and child vocabulary.

This finding raises critical questions regarding the properties of verbal communicative input that relate to children's growth in vocabulary production. What is it about maternal speech that enhances children's language learning? Is it the amount of talk, the variety of words used, the pragmatic aspects of the interaction, or some combination of each? Do specific features of communicative input play different roles in child lexical development in different SES or cultural groups? These are broad questions for which we have no definitive answers, although our results, coupled with results of previous research, can take us one step closer to understanding these larger issues.

Our findings suggest that although quantity of maternal verbal input differs across social class (Hart \& Risley, 1995), sheer quantity of input is not the best predictor of growth in child vocabulary production for children from low-income families, and thus amount of talk directed to children may not be the driving force behind the differences in average child vocabulary size seen across social classes. That is, a different combination of communicative factors may relate to child lexical development in low-income versus middle-class families. For example, it may be that low-income mothers, on average, use more nonverbal means of communication, such as pointing gestures, when communicating with young children. A recent comparison of a subsample of these low-income mothers with middle-class mothers and with mothers of children with otitis media showed that mothers from the low-income group produced significantly more points per minute than the other two groups of mothers during interaction with their 14-month-old children (Pan, Rowe, \& Yont, 2001). In the current study, the total number of maternal pointing gestures did relate to growth in child vocabulary production, a finding that may or may not be replicated in samples of families of dif- 
ferent social class or when examining a broader range of communicative gestures.

Another possible explanation for differences in our findings and those from earlier studies is context. First, the observation in the current study was relatively brief, a potential limitation; longer observations might have advantaged more talkative mothers. Furthermore, in the current study dyads were asked to begin with the book and move on to other materials when they wished. Previous research has shown that middle-class and working-class mothers tend to talk more and use more varied vocabulary during book reading, compared with toy play, with their children (Hoff-Ginsberg, 1991). It is possible that by beginning with a book, variation in maternal talkativeness in our study might have been reduced or variation in lexical diversity increased, thus highlighting the influence of mother word types over tokens in predicting children's vocabulary use. However, the wide variation observed in maternal talkativeness makes this seem unlikely. Furthermore, dyads on average spent less than 2 of the $10 \mathrm{~min}$ allotted interacting around the book. Although time spent with the book was positively correlated with maternal measures of communication (types, as well as tokens and pointing), it was not related to child vocabulary production at any age. Thus, although book reading is no doubt facilitative of mother-child communication - perhaps particularly so for mothers whose temperament, educational experience, or culture leads them to be more reticent - it is unlikely that the opportunity for mothers to spend time reading or talking about a book with their children fully explains the pattern of results observed here.

A more plausible explanation for the greater influence of lexical diversity over quantity of maternal input might be a sociocultural one, that is, that mothers in different sociocultural groups may use language in pragmatically different ways or that pragmatic use relates to vocabulary diversity in different ways. Closer examination of the pragmatic features of maternal talk in low-income samples would help determine how these mothers differ as a group from typical middle-class mothers in the kind of speech they direct to their children. Previous work in this area has shown that mothers of different social classes differ in their general communicative styles, with low-income parents using more prohibitions, discouragements, and directives (Hart \& Risley, 1995; Hoff-Ginsberg, 1991) than middle- or upper-middle-class parents. Therefore, one might argue that the generally positive effects of amount of parental talk on child language growth found with middle-class families may be compromised in fami- lies where the features of talk differ in substantive ways. However, many similarities have also been reported when comparing pragmatic features of talk across social classes. For example, Hoff-Ginsberg (1991) found that although upper-middle-class mothers and working class mothers did differ on the number of directives used with children, as presented previously, they did not differ on the number of conversation-eliciting utterances produced or in the total time spent in joint attention episodes, both features of interaction previously found conducive to language learning (Hoff-Ginsberg, 1990; Tomasello \& Farrar, 1986). There is scarce and conflicting evidence, then, about differences in the communicative purposes for which language is used between mothers of varying social classes.

It is also possible, as suggested by Hoff and Naigles (2002), that social-pragmatic features of language may be particularly important during the earliest stages of language learning, but that by 24 months, a time when children are more experienced in participating in joint attentional episodes, the data-driven aspects of input are more relevant for vocabulary development. This hypothesis is congruent with the results of the present study, namely, that the effect of maternal word types was most pronounced around child age 24 months. Other work with older children from low-income families (Weizman \& Snow, 2001) has also shown that diversity of word use is a better predictor of child vocabulary outcome than is total quantity of verbal input. The data-providing measure (sophisticated word exposure) and the social-pragmatic measure (informative support) examined by Weizman and Snow (2001) were collinear predictors and thus explained the same amount of variance (approximately $35 \%$ ) in children's language comprehension. Therefore, both types of input related to child lexical outcomes by age 5 , yet considerable variation was still unexplained. Similarly, in the current study factors more distal to the child, such as maternal language and literacy skills and depression, begin to become more influential for vocabulary development as children become more skilled communicative partners (in our case, by 36 months).

In sum, our result showing a null effect of maternal tokens on growth in child vocabulary production contradicts previous results with different samples and raises questions about social class differences in maternal input and child language learning. It is clear that more research is needed with samples from diverse SES and cultural backgrounds to examine further this phenomenon. Maternal pointing had a significant effect on acceleration in 
child vocabulary production, although the effect disappeared when word types were considered. However, it is important not to overlook the fact that nonverbal input has a positive effect on growth in child vocabulary production and in this analysis had a stronger effect than total amount of talk. One possible explanation for a pointing effect is that the gesture provides additional help to the child in identifying a verbal referent. We know from previous analyses with a smaller sample of these same families at child age 14 months (Rowe, 2000) that most of the maternal pointing gestures occurred simultaneously with speech. In addition, most of the maternal points were used in the context of directing the child's attention or discussing a joint focus of attention. Previous research suggests that children in their 2 nd year of life are very good at using external referential cues, such as pointing, as a means of facilitating word learning (Akhtar \& Tomasello, 2000). Therefore, it may simply be that the mothers who point frequently during interaction with their children are enhancing access to the meaning of their verbal input and thus facilitating the rate of growth in their children's vocabulary production.

Maternal verbal language aptitude and literacy skills were a significant predictor of growth in child vocabulary production and were more influential than maternal education, perhaps because of the limited variation in education in this sample. Despite the fact that most mothers had 12 years of education, their scores on the standardized verbal aptitude and literacy tests were varied and were highly predictive of their children's vocabulary growth. This result is similar to previous results found with middle-class samples (Bornstein et al., 1998; NICHD, 2000). There are multiple ways to interpret this finding. One perspective is the genetic view that the mothers with higher scores on the language and literacy composite have higher verbal intelligences (the WAIS is a verbal intelligence test) and thus tend to have children with greater verbal intelligences and abilities. An alternate perspective is that mothers with higher language and literacy skills interact with their children differently than do mothers with lower language and literacy skills. Recent work by Hoff (2003) offers support for maternal language characteristics as the primary pathway through which socioeconomic effects on children's vocabulary are manifest.

It is important to note that in the current study, language and literacy affected growth in child vocabulary production directly, as well as indirectly, through maternal word types (controlling for depression). Therefore, the maternal language and literacy effect does not seem to be entirely mediated by maternal input, and we should look to other areas to try and tease out the mechanisms explaining this effect.

The finding of a direct effect of maternal depression on growth in child vocabulary production concurs with previous work on the development of children with depressed parents and extends these findings to language development. Previous work has found that children of depressed mothers are more likely to show signs of depression and anxiety themselves (Radke-Yarrow et al., 1992), that depressed mothers tend to talk less to their children than healthy mothers (Breznitz \& Sherman, 1987; Lovejoy et al., 2000), and that children of depressed mothers tend to talk less with their mothers during lunch time (Breznitz \& Sherman, 1987). The results of the current study suggest that the children of depressed mothers also have slower growth in vocabulary production than their peers. The effect of depression found here was greater as the children aged, suggesting either that mothers who were depressed early on stayed depressed or that the very early effects of maternal depression had greater ramifications as children aged. Results suggesting that the effect of depression increases with time have also been found in other studies looking at different aspects of children's development (Radke-Yarrow et al., 1992). It is important to interpret this result with caution, however, because our outcome measure was children's vocabulary use during interaction with their mothers. It may be that these same children, in contexts other than interaction with a potentially depressed parent, may use more diverse vocabulary.

It is clear that communication with infants and young toddlers is a total package of verbal and nonverbal, linguistic and emotional interaction, and that mothers differ in the extent to which they draw on both verbal and nonverbal resources in the input they provide to children. Previous research, primarily with middle-class samples, has shown that both quantity and variety of verbal input are related to children's vocabulary growth (Hart \& Risley, 1995; Huttenlocher et al., 1991; Weizman \& Snow, 2001). Results from this study of more than 100 low-income families concur with previous results in regard to the importance of addressing a wide range of vocabulary words to children. The null result here regarding the role of quantity of input in child lexical development encourages more research investigating the separate and combined effects of data-providing verbal and nonverbal measures as predictors of child vocabulary growth. This may be particularly important as we investigate these phenomena in more diverse samples where different aspects of 
maternal communicativeness may relate to child vocabulary skills.

The finding that maternal language and literacy skills and depression have a direct effect on growth in child vocabulary production is evidence that there are other measurable factors besides communicative input that enhance or impede child language learning. By continuing to explore the predictive power of additional aspects of children's early environments we will develop a more complete understanding of the specific factors related to child language development, and we can thus provide further explanations for the vast individual differences in rate of vocabulary acquisition during the first 3 years.

A final note about methodology is in order. In the current study we used individual growth modeling to investigate the role of time-varying communicative input predictors on growth in child vocabulary production between 14 and 36 months. This approach offered two primary advantages. First, we were able to use all the available data from all participants rather than setting aside cases with one or more missing waves of data. Given the pervasive (and often unacknowledged) problems of missing data and sample attrition in longitudinal research, avoiding the potential bias introduced by deleting cases is critical if we are to get an accurate picture of input and development across time. The other primary advantage of the methodology employed here is that we were able to consider input to children as varying across time rather than having to rely on communicative input at a single time point as the predictor of child vocabulary growth. The use of time-varying predictors here proved justified, given that both maternal word types and tokens increased significantly with child age and ability (Rowe, Pan, \& Ayoub, in press). In addition to potential social class or age-dependent differences in the effects of adult input on children's vocabulary growth discussed earlier, then, the differing methods employed here and elsewhere should be noted when comparing results across studies.

\section{References}

Abidin, R. (1995). Parenting Stress Index (PSI). Parenting Stress Index professional manual (3rd ed.). Odessa, FL: Psychological Assessment Resources.

Akhtar, N., \& Tomasello, M. (2000). The social nature of words and word learning. In R. M. Golinkoff, K. HirshPasek, L. Bloom, L. Smith, A. Woodward, \& N. Akhtar et al. (Eds.), Becoming a word learner: A debate on lexical acquisition (pp. 115-135). Oxford, England: Oxford University Press.
Bauer, D. J., Goldfield, B. A., \& Reznick, J. S. (2002). Alternative approaches to analyzing individual differences in the rate of early vocabulary development. Applied Psycholinguistics, 23, 313-335.

Bayley, N. (1993). Bayley Scales of Infant Development: Manual (2nd ed.). New York: Psychological Corporation, Harcourt Brace \& Company.

Belle, D. (1990). Poverty and women's mental health. American Psychologist, 45, 385-389.

Belsky, J. (1984). The determinants of parenting: A process model. Child Development, 55, 83-96.

Bloom, L., \& Lahey, M. (1978). Language development and language disorders. New York: Wiley.

Bornstein, M. H., Haynes, M. O., \& Painter, K. M. (1998). Sources of child vocabulary competence: A multivariate model. Journal of Child Language, 25, 367-393.

Bornstein, M. H., Tamis-LeMonda, C. S., \& Haynes, M. O. (1999). First words in the second year: Continuity, stability, and models of concurrent and predictive correspondence in vocabulary and verbal responsiveness across age and context. Infant Behavior and Development, $22,65-85$.

Breznitz, Z., \& Sherman, T. (1987). Speech patterning of natural discourse of well and depressed mothers and their young children. Child Development, 58, 395-400.

Brown, R. (1973). A first language. Cambridge, MA: Harvard University Press.

Carle, E. (1983). The very hungry caterpillar. New York: Putnam.

Corkum, V., \& Dunham, P. (1996). The Communicative Development Inventory-WORDS Short Form as an index of language production. Journal of Child Language, 23, 515-528.

Day, A. (1996). Good dog Carl. New York: Simon \& Schuster.

DeTemple, J. M., \& Snow, C. E. (1996). Styles of parentchild book-reading as related to mothers' views of literacy and children's literacy outcomes. In J. Shimron (Ed.), Literacy and education: Essays in honor of Dina Feitelson (pp. 49-68). Cresskill, NJ: Hampton.

Fenson, L., Dale, P., Reznick, J. S., Bates, E., Thal, D., \& Pethick, S. (1994). Variability in early communicative development. Monographs for the Society for Research in Child Development, 59(5, Serial No. 242).

Goldfield, B. A., \& Reznick, J. S. (1990). Early lexical acquisition: Rate, content, and the vocabulary spurt. Journal of Child Language, 17, 171-183.

Hart, B., \& Risley, T. R. (1995). Meaningful differences in the everyday experience of young American children. Baltimore: Brooks.

Hedeker, D., \& Gibbons, R. D. (1997). Application of random-effects pattern-mixture models for missing data in longitudinal studies. Psychological Methods, 2, 64-78.

Hoff, E. (2003). The specificity of environmental influence: Socioeconomic status affects early vocabulary development via maternal speech. Child Development, 74, $1368-1378$.

Hoff, E., \& Naigles, L. (2002). How children use input to acquire a lexicon. Child Development, 73, 418-433. 
Hoff-Ginsberg, E. (1990). Maternal speech and the child's development of syntax: A further look. Journal of Child Language, 17, 85-99.

Hoff-Ginsberg, E. (1991). Mother-child conversation in different social classes and communicative settings. Child Development, 62, 782-796.

Hoff-Ginsberg, E. (1998). The relation of birth order and socioeconomic status to children's language experience and language development. Applied Psycholinguistics, 19, $603-629$.

Huttenlocher, J., Haight, W., Bryk, A., Seltzer, M., \& Lyons, T. (1991). Early vocabulary growth: Relation to language input and gender. Developmental Psychology, 27, 236-248.

Iverson, J. M., Capirci, O., \& Caselli, M. C. (1994). From communication to language in two modalities. Cognitive Development, 9, 23-43.

Iverson, J. M., Capirci, O., Longobardi, E., \& Caselli, M. C. (1999). Gesturing in mother-child interactions. Cognitive Development, 14, 57-75.

Little, R. J. A., \& Rubin, D. B. (1987). Statistical analysis with missing data. New York: Wiley.

Love, J., Kisker, E., Ross, C., Schochet, P., Brooks-Gunn, J., Paulsell, D., et al. (2002). Making a difference in the lives of infants and toddlers and their families: The impacts of Early Head Start. Executive summary prepared for the Administration of Children and Families, U.S. Department of Health and Human Services, Washington, DC.

Lovejoy, M. C., Graczyk, P. A., O'Hare, E., \& Newman, G. (2000). Maternal depression and parenting behavior: A meta-analytic review. Clinical Psychology Review, 20, $561-592$.

MacWhinney, B. (2000). The CHILDES Project: Tools for analyzing talk. Mahwah, NJ: Erlbaum.

Milner, J. (1986). The Child Abuse Potential Inventory: Manual. Webster, NC: PSYTEC.

Murphy, C. M. (1978). Pointing in the context of a shared activity. Child Development, 49, 371-380.

National Institute of Child Heath and Human Development Early Child Care Research Network. (2000). The relation of child care to cognitive and language development. Child Development, 71, 960-980.

Pan, B. A., Imbens-Bailey, A., Winner, K., \& Snow, C. E. (1996). Communicative intents of parents interacting with their young children. Merrill-Palmer Quarterly, 42, $248-266$

Pan, B. A., \& Rowe, M. L. (1999, July). Sources of variation in the amount mothers talk and gesture in interaction with their 14-month-old children. Paper presented at the eighth meeting of the International Congress for the Study of Child Language, San Sebastian, Basque Country, Spain.

Pan, B. A., Rowe, M. L., Spier, E., \& Tamis-LeMonda, C. (2004). Measuring productive vocabulary of children in low-income families: Concurrent and predictive validity of three sources of data. Journal of Child Language, 31, 587-608.

Pan, B. A., Rowe, M. L., \& Yont, K. (2001, April). Variation among parents in gesture use accompanying child-directed speech. Poster presented at the biennial meeting of the Society for Research in Child Development, Minneapolis, MN.

Pan, B. A., Snow, C. E., \& Willett, J. B. (1993). Modeling language growth: Measures of lexical, morphosyntactic, and conversational skill for early child language. Harvard University Graduate School of Education manuscript.

Radke-Yarrow, M., Nottelmann, E., Martinex, P., Fox, M. B., \& Belmont, B. (1992). Young children of affectively ill parents: A longitudinal study of psychosocial development. Journal of the American Academy of Child Adolescent Psychiatry, 31, 68-76.

Radloff, L. S. (1977). The CES-D scale: A self report depression scale for research in the general population. Applied Psychological Measurement, 1, 385-401.

Raudenbush, S. W., \& Bryk, A. S. (2002). Hierarchical linear models: Applications and data analysis methods. Thousand Oaks, CA: Sage.

Rescorla, L. A. (1980). Overextension in early language development. Journal of Child Language, 7, 321-335.

Rollins, P. R. (2003). Caregiver contingent comments and subsequent vocabulary comprehension. Applied Psycholinguistics, 24, 221-234.

Rowe, M. L. (2000). Pointing and talk by low-income mothers and their 14-month-old children. First Language, 20, 305-330.

Rowe, M. L., Pan, B. A., \& Ayoub, C. (in press). Predictors of variation in maternal talk to children: A longitudinal study of low-income families. Parenting: Science and Practice.

Singer, J. D., \& Willett, J. B. (2003). Applied longitudinal data analysis: Modeling change and event occurrence. Oxford, England: Oxford University Press.

Snow, C. E., Burns, S., \& Griffin, P. (1998). Preventing reading difficulties in young children. Washington, DC: National Academy Press.

Snow, C. E., Pan, B. A., Imbens-Bailey, A., \& Herman, J. (1996). Learning how to say what one means: A longitudinal study of children's speech act use. Social Development, 5, 56-84.

Tamis-LeMonda, C. S., Bornstein, M. H., \& Baumwell, L. (2001). Maternal responsiveness and children's achievement of language milestones. Child Development, 72, $748-767$.

Tomasello, M., \& Farrar, M. J. (1986). Joint attention and early language. Child Development, 57, 1454-1463.

Vandell, D. L. (1979). A microanalysisof toddlers' social interaction with mothers and fathers. Journal of Genetic Psychology, 134, 299-312.

Vernon-Feagans, L. (1996). Children's talk in communities and classrooms. Cambridge, MA: Blackwell.

Wechsler, D. (1981). Manual for Wechsler Adult Intelligence Scale-Revised. San Antonio, TX: Psychological Corporation.

Weizman, Z. O., \& Snow, C. E. (2001). Lexical input as related to children's vocabulary acquisition: Effects of sophisticated exposure and support for meaning. Developmental Psychology, 37, 265-279. 
Woodcock, R. (1978). Development and standardization of the Woodcock-Johnson psycho-educational battery. Hingham, MA: Teaching Resources.

\section{Appendix}

The simplest Level 2 specifications are unconditional growth models, in which we include no substantive predicators and instead allow each Level 1 parameter to vary randomly around its population mean:

$$
\begin{aligned}
& \pi_{0 i}=\beta_{00}+u_{0 i} \\
& \pi_{1 i}=\beta_{10}+u_{1 i} \\
& \pi_{2 i}=\beta_{20}+u_{2 i}
\end{aligned}
$$

Conceptually, each submodel in Equation A1 treats the Level 1 growth parameters as outcomes. The three fixed effects $\left(\beta_{00}, \beta_{10}\right.$, and $\left.\beta_{20}\right)$, therefore, served as Level 2 intercepts, representing the average true level of vocabulary production at 14 months, the average true instantaneous rate of change at 14 months, and the average acceleration in child vocabulary production over time. The Level 2 residuals, $u_{0 i}, u_{1 i}$, and $u_{2 i}$, represent the deviation of each child's growth parameters from the population average.

Following Singer and Willett (2003, pp. 80-85), we can derive the composite specification of the multilevel model for change by substituting the Level 2 submodels in Equation A1 back into the Level 1 model in Equation 1 and rearranging terms (collecting together the structural and stochastic portions of the model) to find:

$$
\begin{aligned}
\text { CTYPES }_{i t}= & {\left[\beta_{00}+\beta_{10}(\mathrm{AGE}-14)_{i t}+\beta_{20}(\mathrm{AGE}-14)_{i t}^{2}\right] } \\
& +\left[u_{0 i}+u_{1 i}(\mathrm{AGE}-14)_{i t}+u_{2 i}(\mathrm{AGE}-14)_{i t}^{2}+\varepsilon_{i t}\right]
\end{aligned}
$$

Mathematically, the composite specification in Equation A2 is identical to the Levels 1 and 2 specifications in Equations 1 and A1. We present the composite specification to clarify precisely which model we fit to the data and to highlight the complex behavior of the residuals assumed by the postulated model.

The final step in model specification was to invoke some distributional assumptions about the behavior of these residuals, both the Level 1 residuals, $\varepsilon_{i t}$, and the Level 2 residuals, $u_{0 i}, u_{1 i}$, and $u_{2 i}$. The fact that the children produced very few or no word types at Wave 1 resulted in a unique and complex pattern of variation in the data, where there was very little variation in child types at Wave 1 yet a relatively large amount at Waves 2 and 3 . Thus, the standard assumptions of homogeneity and autocorrelation did not fit particularly well, as residual variance increased over time and variance at Wave 1 was not related to variance at Wave 2 or 3 . We therefore explored several alternative distributional assumptions (including unstructured, heterogeneous compound symmetric, heterogeneous autoregressive, and Toeplitz) for both sets of residuals to augment the standard error specification with an additional set of assumptions about $\varepsilon_{i t}$ at Level 1. Following strategies outlined in Singer and Willett (2003), we empirically compared the goodness-of-fit statistics associated with alternative error-covariance structures. The $-2 \mathrm{LL}$ statistic for the unstructured model was 2,116 versus 2,481 with the standard model, substantially less despite the additional parameters for the error-covariance matrix. This led us to adopt a completely unstructured error-covariance matrix at Level 1 (for $\varepsilon_{i t}$ ) and a highly constrained error-covariance matrix at Level 2 (for $u_{0 i}, u_{1 i}$, and $u_{2 i}$ ). At Level 1, then, we estimated separate residual variances for each wave (as well as the covariances among them) and let these parameters take on the values that the data demand. The appeal of the unstructured approach is that it places no restrictions on the structure of the error-covariance matrix and always results in the smallest deviance statistic. The trouble with the unstructured approach is the increase in the number of parameters to estimate and the use of additional degrees of freedom. Because of the behavior of the data, the unstructured error-covariance matrix was the most parsimonious structure we could fit despite the additional parameters. At Level 2, we allowed the linear term, $\pi_{1 i}$, to vary freely but we completely fixed the intercept, $\pi_{0 i}$, and curvature, $\pi_{2 i}$, terms, setting $u_{0 i}$ and $u_{2 i}$ in Equation A2 to 0 . This approach of fixing Level 2 residuals was adopted by others doing similar analyses (Raudenbush \& Bryk, 2002) and leads to the following simplified composite growth model:

$$
\begin{aligned}
\text { CTYPES }_{i t}= & {\left[\beta_{00}+\beta_{10}(\mathrm{AGE}-14)_{i t}+\beta_{20}(\mathrm{AGE}\right.} \\
& \left.-14)_{i t}^{2}\right]+\left[u_{1 i}(\mathrm{AGE}-14)_{i t}+\varepsilon_{i t}\right]
\end{aligned}
$$

Having specified Equation A3, it was relatively straightforward to add substantive person-level predictors to the right-hand sides of the equation to allow us to assess whether child and maternal characteristics are associated with variation in the individual growth parameters. The primary goal of this analysis was to identify predictors that explain variation in the instantaneous rate of change and in acceleration over time in child vocabulary production. Although we also examined the effect of predictors on initial status, we did not anticipate significant results, as there was little variation in child vocabulary production at 14 months.

\footnotetext{
${ }^{1}$ We conducted analyses to determine whether missing data might bias the results. Individual growth models are sound as long as the unobserved waves are either missing completely at random (MCAR) or missing at random (MAR; Little \& Rubin, 1987). When data are MCAR, the observed values are a random sample of all the values that could have been observed had there been no missing data. It is not likely that our data are MCAR, as there are more missing data at later time points, suggesting attrition. When data are MAR, a much less restrictive assumption, the probability of missingness, can depend on any observed data for either the predictors or the outcome. As Singer and Willett (2003) noted, "The allowance for dependence upon observed outcome data can account for a
} 
multitude of sins, often supporting the credibility of the MAR assumption even when MCAR ... assumptions seem far-fetched" (p. 158). In making this assumption, we are arguing that it is safe to assume that the probability of missingness is unrelated to observed concurrent outcomes. For these data, it seems unlikely that parents would be unwilling to participate because of their child's vocabulary level at a given occasion.

${ }^{2}$ At Level 1, the goal of centering is to ensure that the parameters in have inherent meaning so that when the Level 2 models are specified using these Level 1 parameters as outcomes, the results have direct inherent meaning. Had we not centered age in the Level 1 model, the first two individual growth parameters would be virtually uninterpretable, as they would have represented children's vocabulary production and instantaneous rate of change in vocabulary production at birth (age 0 ). Following the work of Huttenlocher et al. (1991), we chose to center age at a time within the range of the data when children are just beginning to produce words. We explored alternate centering constraints including ages between 9 and 15 months, and determined that a model centered at 14 months fit the data best. We also explored the option of centering child age at either 24 or 36 months. Although this, too, would have produced Level 1 parameters with inherent meaning, we discovered that doing so perturbed the stochastic portion of the model, precluding us from estimating the variance component associated with the Level 2 slope $\left(u_{1 i}\right)$. We evaluated the sensitivity of the results to this centering decision and found that the chosen model fit better and the substantive results remained unchanged. Thus, our rationale for centering age at 14 months was twofold: (a) it ensured that the individual growth parameters had clear meaning, and (b) it allowed us to simplify model specification by fixing the variance component associated with the intercept. 